\title{
Run-in Period
}

National Cancer Institute

\section{Source}

National Cancer Institute. Run-in Period. NCI Thesaurus. Code C98779.

A period in a clinical study that occurs before the commencement of the primary clinical study investigation, during which subjects may be assessed for suitability in the clinical study, withdrawn from existing therapy, trained in study methodology or evaluated for any other protocol-specified reason. 